\title{
Siah2 modulates sex-dependent metabolic and inflammatory responses in adipose tissue to a high-fat diet challenge
}

Sujoy Ghosh ${ }^{1,2}$, Jessica L. Taylor ${ }^{1}$, Tamra M. Mendoza ${ }^{1}$, Thanh Dang ${ }^{1}$, David H. Burk' , Yongmei Yu', Gail Kilroy ${ }^{1}$ and

Z. Elizabeth Floyd ${ }^{1 *}$ (i)

\begin{abstract}
Background: The obesity-related risk of developing metabolic syndrome is higher in males than in females of reproductive age, likely due to estrogen-mediated reduced adipose tissue inflammation and fibrosis with hypertrophied adipocytes. Depletion of the ubiquitin ligase Siah2 reduced white adipose tissue inflammation and improved glucose metabolism in obese male mice. Siah2 is a transcriptional target of estrogen, but data is lacking about the effect of Siah2 on adipose tissue of females. We therefore evaluated the impact of Siah2 deficiency on white and brown adipose tissue in females of reproductive age.
\end{abstract}

Methods: Body composition, adipose tissue morphology, brown adipose tissue gene, and protein expression and adipocyte sizing were evaluated in wild-type and Siah2KO female and male mice fed a low-fat or high-fat diet. Glucose and insulin tolerance, fasting glucose, insulin, fatty acids and triglycerides, and gene expression of inflammation markers in perigonadal fat were evaluated in wild-type and Siah2KO female mice. Microarray analysis of brown fat gene expression was carried out in both sexes. Statistical analysis was assessed by unpaired two-tailed $t$ test and repeated measures ANOVA.

Results: Siah2 deficiency improves glucose and insulin tolerance in the presence of hypertrophied white adipocytes in high-fat-fed female mice with percent fat comparable to male mice. While previous studies showed Siah2KO reduces the white adipose tissue inflammatory response in male mice, the response in females is biased toward the upregulation of M2-like markers in white adipose tissue. In contrast, loss of Siah2 leads to increased whitening of brown fat in males, but not in females. This corresponded to increased expression of markers of inflammation ( $F 4 / 80, \mathrm{CCl} 2)$ and thermogenic genes (Pgclalpha, Dio2, Ucp-1) and proteins (PGC-1a, UCP-1) in females. Contrary to expectations, increased expression of thermogenic markers in females was coupled with a downregulation of ERalpha and ERRgamma protein levels.

Conclusions: The most striking sex-related effect of Siah2 deficiency is reduced whitening of brown fat in high-fat-fed females. Protection from accumulating unilocular adipocytes in the brown fat corresponds to increased expression of thermogenic genes and proteins in female, but not in male mice. These results raise the possibility that Siah2 contributes to the estrogen-related effects on brown fat function in males and females.

Keywords: Adipose tissue, Estrogen, Estrogen receptor, Estrogen-related receptor, Inflammation, Obesity, Sex, Siah2, Ubiquitin

\footnotetext{
* Correspondence: Elizabeth.Floyd@pbrc.edu

'Pennington Biomedical Research Center, Baton Rouge, LA 70808, USA

Full list of author information is available at the end of the article
}

(c) The Author(s). 2019 Open Access This article is distributed under the terms of the Creative Commons Attribution 4.0 International License (http://creativecommons.org/licenses/by/4.0/), which permits unrestricted use, distribution, and reproduction in any medium, provided you give appropriate credit to the original author(s) and the source, provide a link to the Creative Commons license, and indicate if changes were made. The Creative Commons Public Domain Dedication waiver (http://creativecommons.org/publicdomain/zero/1.0/) applies to the data made available in this article, unless otherwise stated. 


\section{Background}

Obesity increases the risk of developing metabolic syndrome, a collection of risk factors for type 2 diabetes that includes insulin resistance and dyslipidemia. The connection between obesity and metabolic dysfunction is more common in males than females of reproductive age in rodents [1-3] and humans [4,5]. Although women have an overall higher percent body fat, increased lower body subcutaneous adipose tissue in women is thought to confer protection against obesity-related insulin resistance that is typically associated with abdominal visceral fat more common in men [6-9]. However, this protection diminishes in postmenopausal females as visceral fat increases, pointing to the importance of sex hormones in influencing fat distribution [10, 11]. Although estrogendriven accumulation of subcutaneous fat protects against obesity-related insulin resistance [10], recent trends indicate a rise in metabolic syndrome among younger females, mainly driven by increased intra-abdominal visceral obesity [12]. This reinforces the strong correlation between abdominal adipose tissue and the adverse metabolic consequences of obesity in males or females.

Metabolic complications with obesity arise from the inability of adipose tissue to expand and safely store the excess lipids. Adipose tissue can expand by producing new adipocytes (hyperplasia) or increasing the volume of existing fat cells (hypertrophy). Abdominal adipose tissue expands by either route, but is less able to generate new adipocytes than subcutaneous adipose tissue [13]. When the lipid storage capacity of the hypertrophied adipocytes is exceeded, the lipid is stored in the skeletal muscle and liver, leading to insulin resistance [14, 15]. This coincides with the increased release of fatty acids from the enlarged adipocytes, recruitment of macrophage to the adipose tissue, and higher expression of pro-inflammatory proteins that signifies chronic, low-grade inflammation in the adipose tissue.

Estrogens affect the relationship between adipocyte hypertrophy, adipose tissue inflammation and insulin responsiveness in males and females [9]. Estrogen-responsive receptor alpha $(E R \alpha)$ depletion in visceral fat leads to adipocyte hypertrophy and adipose tissue inflammation in male and female mice [16]. However, when ER $\alpha$ is deleted specifically in adipocytes, sex-related differences emerge in which adipose tissue expansion via adipocyte hypertrophy occurs in females, but not male mice. Even so, the females are protected from adipose tissue inflammation and impaired glucose metabolism despite adipocyte hypertrophy [16].

Obesity-related changes in adipocyte size and adipose tissue inflammation also occur in brown adipose tissue, and sex-related differences in adipose tissue extend to brown fat as well [17]. Women have increased brown adipose tissue mass compared to men [18, 19], and estrogen activates brown fat thermogenesis, but there is no clear evidence of higher energy expenditure in women. Brown adipose tissue's ability to use lipids as fuel to drive adaptive thermogenesis is negatively impacted by obesity as the brown fat undergoes "whitening" with the accumulation of large, unilocular lipid droplets characteristic of white fat [20]. In male mice, this is accompanied by brown adipose tissue inflammation as macrophages surround the dysfunctional "whitened" brown adipocytes [21], forming the characteristic "crown-like structure" indicative of macrophages surrounding lipid droplet remnants from dead adipocytes [22]. While the anti-inflammatory properties of estrogen are well-known [23, 24], sex-related differences in estrogen signaling in brown adipose tissue with obesity are not well described.

Our earlier studies of the mammalian homolog of the Drosophila ubiquitin ligase seven-in-absentia-2 (Siah2) in adipose tissue from obese male mice showed that Siah2 deficiency leads to adipocyte hypertrophy in white adipose tissue, but protects against adipose tissue inflammation and the associated insulin resistance [25]. Siah2 interacts with the peroxisomal proliferator-activated receptor gamma (PPARY) [26], a nuclear receptor that regulates lipid metabolism as well as inflammatory responses in adipose tissue [27], and selectively regulates PPAR $\gamma$ activity in gonadal adipose tissue [25]. Siah2 is also a transcriptional target of the nuclear receptor ER $\alpha$. In ER $\alpha$-positive breast cancer cells, estrogen stimulates gene expression by upregulating Siah2 transcription and stimulating Siah2-mediated N-CoR degradation [28]. Estrogen-related regulation of Siah2, and its previously observed effects on white adipose tissue, prompted us to examine sex-dependent differences in white and brown adipose tissue inflammation in dietinduced obesity in a systemic Siah2-deficiency (Siah2KO) mouse model.

Here, we show that loss of Siah2 protects against impaired glucose metabolism and disrupts the connection between hypertrophied adipocytes and adipose tissue inflammation in the white adipose tissue of the high-fatfed females, similar to our earlier reports in male mice. Most strikingly, Siah2 deficiency upregulates expression of Pgc1a, Dio2, and Ucp1 in female, but not in male brown fat mice. The change in thermogenic gene expression corresponds to increased protein expression of PGC1 $\alpha$ and UCP1 and less whitening of the female brown fat than observed in the male mice. Unexpectedly, enhanced markers of brown fat thermogenesis in the HFD-fed females correspond to substantially reduced protein expression of the nuclear receptors ER $\alpha$ and ERR $\gamma$ that promote brown fat thermogenesis $[29,30]$. This suggests that sex-related modulation of Siah2 activity in brown fat may act to dampen thermogenic responses to chronic overnutrition in females by regulating ER $\alpha$ and ERR $\gamma$ protein levels in brown fat. 


\section{Methods}

\section{Experimental animals}

Siah2KO mice were generated and maintained as described [25, 31]. Wild-type C57BL/6J mice were obtained from Jackson Laboratories. The female mice were reproductively intact. All animal experiments were approved by the Pennington Biomedical Research Center Animal Care and Use Committee (protocol \#1030). The animals were multi-housed with a 12-h light-dark cycle at $24{ }^{\circ} \mathrm{C}$. At 4 weeks of age, wild-type and Siah2KO male and female mice of similar body weight within each sex were randomly assigned ( $n=8-10$ /group) to a defined $10 \%$ low-fat (LFD; 10\% kcal fat, Research Diets, \#D12450H, sucrose matched to the HFD) or 45\% high-fat (HFD; $45 \%$ kcal fat, Research Diets, \#D12451) diet and were fed ad libitum for 4 months thereafter. Body weight was measured weekly and body composition was measured bi-weekly by NMR. At the end of the study, the mice were euthanized between 8 and 11 AM.

\section{Glucose and insulin tolerance tests}

For the glucose (GTT) and insulin (ITT) tolerance tests, the amount of glucose or insulin administered was normalized to fat-free mass [32], which did not vary significantly among groups $(20.1-/+0.13 \mathrm{~g})$ at 12 weeks on each diet. Mice were fasted $4 \mathrm{~h}$ prior to administering $2 \mathrm{~g} / \mathrm{kg}$ fat-free mass of glucose/mouse (GTT) or $1 \mathrm{U} / \mathrm{kg}$ fat-free mass insulin/mouse (HumulinR) (ITT) by intraperitoneal injection.

\section{Blood chemistry}

Fasting serum glucose levels were measured using a Breeze2 glucometer (Bayer, Leverkusen, Germany). Fasting insulin and leptin levels were assayed via ELISA (Crystal Chem). Serum nonesterified fatty acids (Abcam) and triglycerides (Eagle Diagnostics) levels were assayed according to manufacturers' instructions.

\section{Microarray analysis}

Brown adipose tissue RNA (RNA integrity number $\geq 8$ ) was analyzed for gene expression on Illumina MouseRef-8v2.0 expression arrays. RNA from eight to ten animals/group was combined into three pooled samples/group. Samples from male and female animals were analyzed separately. Raw gene expression signals were background adjusted and quantile normalized using GenomeStudio (V2011.1.Illumina Inc.). For each sample, probes with detection $p$ value $<0.05$ were considered "expressed." These probes were log transformed (base 2), and treatment-specific fold changes were computed as log ratios. The statistical significance of differential expression was ascertained by a regularized $t$ test, based on Bayesian probability models [33]. All statistical analyses were controlled for multiple testing via the false discovery rate (FDR) [34]. The microarray dataset was submitted to Gene Expression Omnibus (GEO) data repository (GSE123990).

\section{Over-representation analysis}

Over-representation analysis (ORA) of biological functions and putative upstream regulators was carried out by subjecting a pre-filtered list of 333 BAT differentially expressed genes for females and 415 genes for males (absolute fold change $>1.3$ and nominal $p$ value $<0.05)$ to Ingenuity Pathway Analysis tool (IPA, QIAGEN Redwood City). Reference gene sets corresponding to "biological functions" (as defined in the Ingenuity Knowledge Base) were analyzed for statistically significant over-representation. Additionally, predictions of changes in the activity status of upstream transcription factors that would be consistent with the observed gene expression changes were also carried out. Biological functions and upstream regulators with a $z$ score $>2.0$ or $<-2.0$ were considered to be activated or inhibited, respectively (http://pages.ingenuity.com/rs/ingenuity/images/0812\%20downstream_effects_analysis_whitepaper.

pdf). Statistical significance of over-represented gene sets was ascertained via Fisher's exact test and corrected for multiple testing via the Benjamini-Hochberg procedure [34].

\section{Quantitative PCR}

Total RNA was purified from inguinal, gonadal, and brown adipose tissue, (200 ng) reverse transcribed, and real-time PCR performed with TaqMan chemistry as described [25]. The results were normalized to hypoxanthine-guanine phosphoribosyltransferase (HPRT), where $\Delta C_{T} \leq-/+0.5$ within each sex [35] for the males and females separately due to significant sex-related differences in housekeeping gene expression and analyzed using the $2^{-\Delta \Delta C T}$ method with wild-type values used as the calibrator. The gene list is provided in Additional file 1.

\section{Preparation of whole cell extracts and immunoblotting}

Adipose tissue was homogenized in a denaturing buffer and processed for immunoblotting as described [25]. Nitrocellulose membranes were incubated with antibodies (Additional file 2) for 1-2 $\mathrm{h}$ at room temperature or overnight at $4{ }^{\circ} \mathrm{C}$. MemCode staining of the nitrocellulose and $\beta$-actin levels were used to confirm equal protein content in each lane.

\section{Immunohistochemistry and immunostaining}

Adipose tissue was fixed in $10 \%$ formalin, then embedded in paraffin, sectioned onto slides, and stained in hematoxylin and eosin (H\&E). Adipose tissue collagen content and fibrosis was determined by trichrome staining. H\&E-stained inguinal and epididymal adipose tissue and laminin stained brown adipocytes (see Additional file 3 B) were 
analyzed using Image J software programmed to measure the area of each adipocyte based on size and shape exclusion limits. Adipocytes or adipocyte remnants surrounded by crown-like structures were manually excluded from analysis. The number of adipocytes counted/experimental condition ranged from 413 to 8442 . The number of adipocytes/fat pad was approximated by converting adipocyte area to a spherical volume, assuming a circular structure for each adipocyte, and then calculating the number of adipocytes $/ \mathrm{cm}^{3}$. After converting the fat pad weight to a volume by assuming the density of each fat pad as equivalent to lipid content at $0.915 \mathrm{~g} / \mathrm{cm}^{3}$, the total volume of each fat pad number was divided by the adipocytes $/ \mathrm{cm}^{3}$ to determine the number of adipocytes/fat pad. A small error is introduced in the calculation as this method does not account for the difference in percent lipid content in gonadal versus inguinal fat depots.

\section{Statistical analysis}

Normal distribution of glucose and insulin levels, food intake, and body weight was assessed using the D'Agostino-Pearson omnibus normality test. Statistical significance for body weight, GTT, and ITT was determined using repeated measures ANOVA. Statistical significance for all other data was determined using an unpaired two-tailed $t$ test. JMP Pro 10.0 (SAS Institute) and GraphPad Prism 5 softwares were used for statistical analyses. Variability was expressed as the mean $-/+$ standard deviation.

\section{Results}

We previously found that despite impaired adipogenesis [36], Siah2KO male mice become obese when challenged with a high-fat diet (HFD) [25]. To further determine if the Siah2KO phenotype is sex-related, we compared body weight and percent fat mass in female and male wild-type and Siah2KO mice fed a low-fat diet (LFD) or HFD for 4 months (Fig. 1a). In contrast to the male Siah2KO mice, body weight gain was attenuated in the female Siah2KO mice compared to the wild-type female mice on the HFD, but not the LFD (Fig. 1a). Female mice of both genotypes had higher adiposity at baseline (Fig. 1b), but the higher rate of fat mass deposition in the male mice resulted in comparable percent fat mass within 1 month of initiating the high-fat diet. However, loss of Siah2 in the males was associated with lower percent fat mass at 4 months. This is reflected in lower fat mass for white and brown adipose tissue relative to total fat mass (Fig. 1c). This did not occur in the HFD-fed Siah2KO female mice, resulting in a significant difference in relative fat mass of gonadal and brown adipose tissue between the male and female Siah2KO mice. Interestingly, the amount of brown fat mass relative to total fat mass in the females was substantially higher than observed in males independent of genotype.

Although the female wild-type and Siah2KO mice had higher adiposity than male mice at baseline and gained $50-60 \%$ of their initial body weight on the HFD, they remained glucose (Fig. 2a) and insulin tolerant (Fig. 2b). The increased responsiveness to insulin in Siah2KO females on the low- or high-fat diet was comparable to our previous findings with Siah2KO males [25] and (Additional file 4 A-C). Unlike our earlier results in male mice, Siah2 deficiency did not correspond to lower fasting glucose or insulin levels in the female mice (Fig. 2c, d). However, loss of Siah2 resulted in a twofold increase in insulin levels with the low-fat diet (Fig. 2d). Like the males in our earlier study, triglyceride levels were unchanged by diet or genotype (Fig. 2e), but increased fat mass in the Siah2KO females on high fat correlated with significantly reduced circulating free fatty acids (Fig. 2f), suggesting an improved ability of adipose tissue to store lipids.

Healthy adipose tissue expansion with excess calorie intake requires expansion via enlarging existing adipocytes and production of new, small adipocytes that increase the capacity to store neutral lipids as adipocytes [37]. Adipose tissue expansion via hypertrophy of existing adipocytes is associated with fibrosis and recruitment of pro-inflammatory immune cells to the adipose tissue, leading to insulin resistance as the adipocytes release free fatty acids into circulation [38]. In our earlier study, a striking feature of the adipose tissue in the Siah2KO male mice was fewer crown-like structures and less adipose tissue fibrosis although the adipocytes were larger in the HFD-fed Siah2KO males compared to HFD-fed wild-type males [25]. These morphological changes were coupled with reduced expression of a wide range of genes that regulate inflammation in adipose tissue [25] (Additional file 4 D). In this study, we found that Siah2 deficiency in the HFD-fed females was also associated with fewer crown-like structures in the gonadal fat pad (Fig. 3a). The female gonadal fat (gWAT) had fewer crown-like structures independent of genotype when compared to male mice, but crown-like structures in the gWAT were further decreased in the Siah2KO females. This corresponded to less fibrosis in the female gonadal fat regardless of genotype (Fig. 3b) and larger adipocytes in the gWAT and IWAT of the females, as seen in the males (Fig. 4 a, c). Thus, depletion of Siah2 in the females resulted in a substantial decrease in morphological indicators of inflammation in white adipose tissue depots even though adipocyte size was increased with the high-fat diet. Our approximation of the number of adipocytes/fat pad indicated increased numbers as well as increased adipocyte size in the 

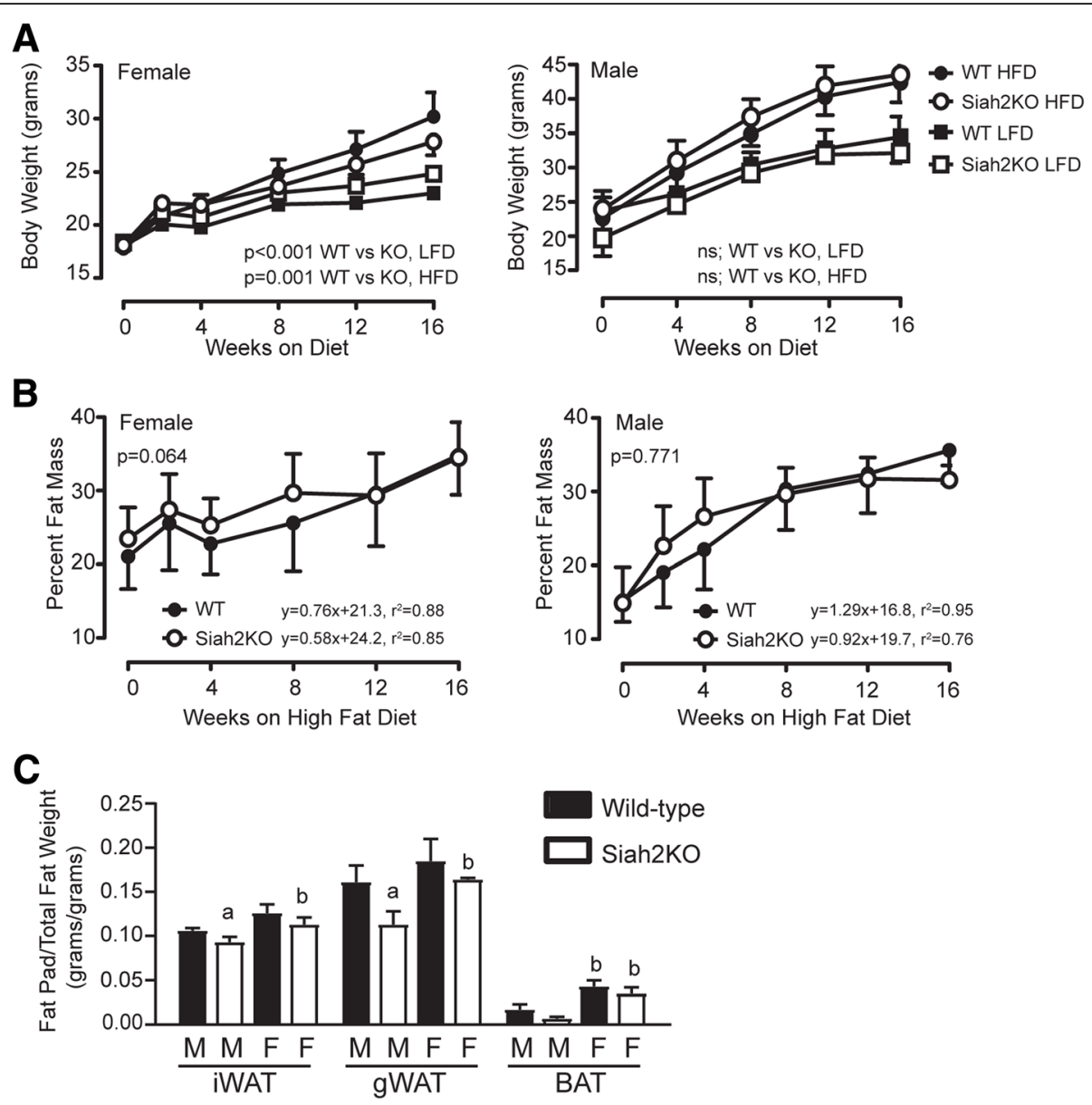

Fig. 1 Wild-type and Siah2KO female mice fed a high-fat diet have percent fat mass comparable to male mice, but higher levels of brown fat relative to total fat mass. a Body weight, $\mathbf{b}$ percent fat mass, and $\mathbf{c}$ fat pad weight/total fat mass were measured in the wild-type (WT) and Siah2KO female and male mice fed a defined low (LFD)- or high (HFD)-fat diet over 16 weeks. Statistical significance was determined using repeated measures ANOVA in $\mathbf{a}$ and $\mathbf{b}$ and two-tailed, unpaired $t$ test in $\mathbf{c}, \mathrm{a}, p<0.05$; within sex comparison between genotypes. $\mathrm{b}, p<0.05$; between sex comparison of related genotype

female gonadal fat, whereas in males, adipocyte hypertrophy was not accompanied by increased numbers (Fig. 4 b). The increased adipocyte size in the inguinal fat of both sexes corresponded to the reduced numbers of adipocytes in each fat pad (Fig. 4d), suggesting the subcutaneous fat tissue expanded via enlarging existing adipocytes in both sexes.

We anticipated that the absence of signs of adipose tissue dysfunction related to inflammation would be reflected in reduced gene expression of inflammation markers in the females. However, as shown in Fig. 5, this was not the case in the gonadal fat of the female Siah2KO mice. Unlike our previous results in male Siah2-deficient mice [25], there was no decrease in macrophage recruitment in the female visceral fat with the HFD $(F 4 / 80, C d 68, C d 11 b)$. Although induction of a proinflammatory marker of M1-like macrophage $(C D 11 c)$ was attenuated in the HFD-fed Siah2KO females, the expression of pro-inflammatory mediators was either unchanged (Ccl2, Ccr2, Tnfalpha, IL-6) or increased
(Pai-1, Saa3) in contrast to that of male HFD-fed Siah2KO mice (Additional file $4 \mathrm{D}$ ). Notably, Siah2 deletion increased Pai-1 and Saa3 gene expression in the insulin-sensitive females independent of diet. However, genes associated with M2-like/homeostatic macrophage (Ym-1, Fizz-1, Arg-1, IL-4) were robustly upregulated only in the HFD-fed Siah2Ko females.

While much of the focus on obesity-induced adipose tissue inflammation has centered on visceral fat depots, inflammatory responses also occur in brown adipose tissue in response to obesity [21, 39, 40]. In this study, we noted that brown fat mass relative to total fat mass in the HFD-fed wild-type or Siah2KO females was significantly higher than the males (Fig. 1c). H\&E and trichrome staining of the brown adipose tissue of the wild-type and Siah2KO males and females showed striking differences in their responses to HFD. As shown in Fig. 6a, brown fat from HFD-fed wild-type and Siah2KO males accumulated unilocular adipocytes 

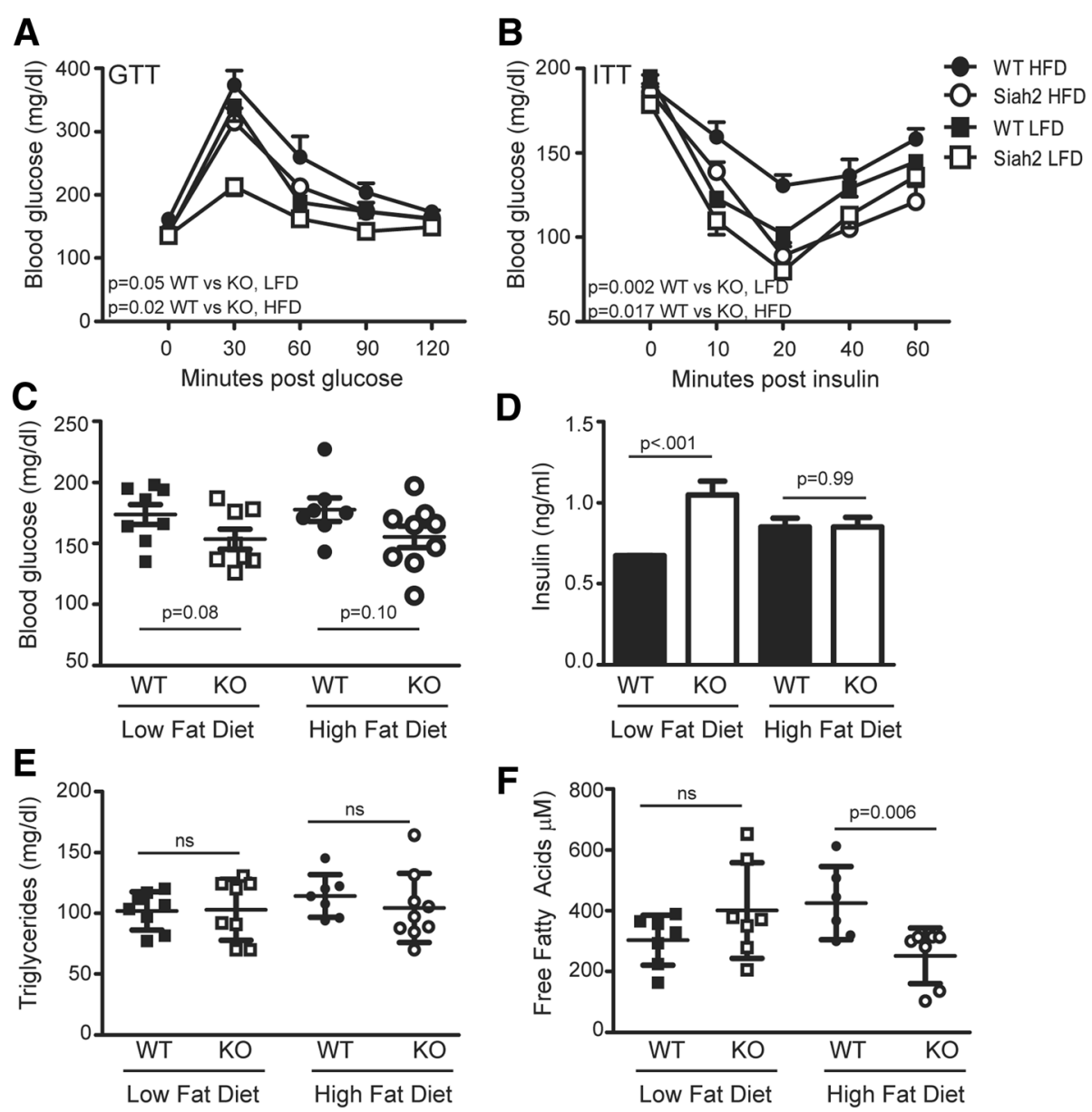

Fig. 2 Carbohydrate metabolism is improved in the lean or obese Siah2KO female mice. a Glucose tolerance and $\mathbf{b}$ insulin tolerance testing were carried out at 12 weeks on the LFD or HFD. c Fasting blood glucose, $\mathbf{d}$ insulin, e triglycerides, and $\mathbf{f}$ free fatty acid levels were assayed after 16 weeks on the LFD or HFD in the female mice. Statistical significance was determined using repeated measures ANOVA in a and b and two-tailed, unpaired $t$ test in $\mathbf{c - f}$

with obesity, and brown fat whitening was increased further with Siah2 deficiency. Unilocular adipocyte accumulation was substantially lower in the HFD-fed wild-type and Siah2KO females, with no additional increases in the knockout animals (an enlarged view is shown in Additional file $3 \mathrm{~A}$ ). Trichrome staining for fibrosis in the brown fat indicated minimal fibrotic changes in the brown fat in either genotype or sex (Fig. 6b). Consistent with accumulating large lipid droplets, the brown adipocytes in the HFD-fed wildtype and Siah2KO males were substantially larger than adipocytes in the HFD-fed female (Fig. 6c). We did not detect a statistically significant diet-dependent change in the number of adipocytes/brown fat pad in either sex or genotype (Fig. 6d). To look more closely at the sex-dependent differences in brown fat (BAT) from the WT and Siah2KO males and females, we carried out a microarray analysis of the brown fat obtained from the HFD-fed mice.
Gene expression analysis identified a total of 26 genes that were differentially regulated in males and 71 genes in females at a nominal $p$ value $<0.001$ and absolute fold change $>1.5$. Of these, only four genes (Rab4a, Erich6, Entpd4, and LOC329575) were differentially expressed in common between male and female BAT samples (Fig. 7), suggesting largely sex-dependent transcriptomic responses in BAT. Gene set overrepresentation analysis in IPA predicted an inhibition of transcription factors related to energy metabolism (Ppargcla) (Fig. 7b) or inflammatory process ( $N f e 2 l 2, \mathrm{Cepbp}$ ) (Fig. 7c) in Siah2-deficient male samples, whereas Siah2-deficient female samples showed a predicted inhibition of the lipogenic transcription factors Srebf1 and Srebf2 (Fig. 7d). These findings are consistent with phenotypic observations, e.g., the inhibition of Ppargcla mRNA signaling in male Siah2KO BAT are likely to reduce fatty acid oxidation and contribute toward whitening, and reductions in Nfe2l2- or Cepbp-encoded proteins are likely to 


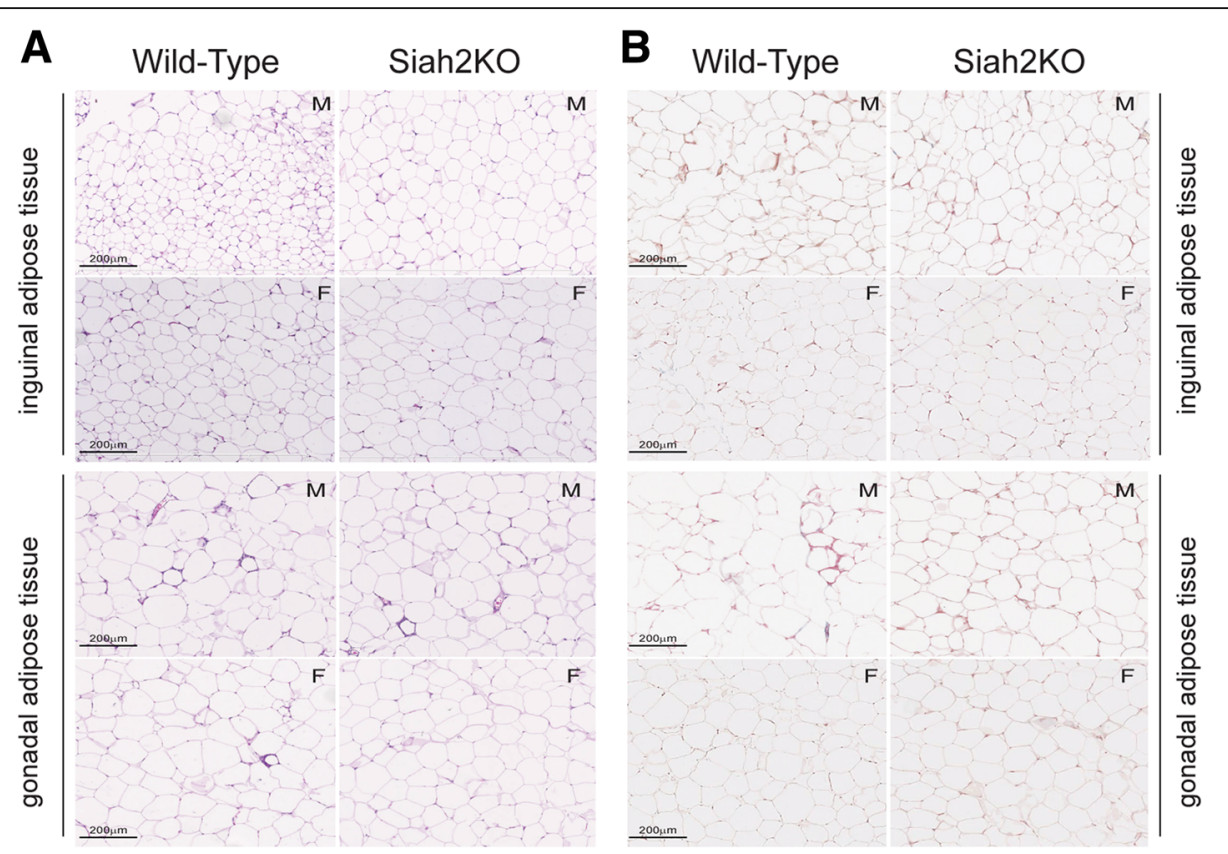

Fig. 3 Female Siah2KO adipocytes increase in size with HFD in white adipose tissue, but accumulate fewer crown-like structures and less fibrosis compared to male white adipose tissue. $\mathbf{a}$ H\&E and $\mathbf{b}$ trichrome staining of HFD male (M) and female (F) wild-type and Siah2KO inguinal and perigonadal fat

contribute to the observed lower inflammatory tone of HFD-fed male Siah2KO samples.

In addition to microarray analysis, we investigated the expression of genes encoding proteins related to lipid metabolism, inflammation, and mitochondrial function. Of the lipid metabolism genes tested, adipose triglyceride lipase (Atgl) and Mid1ip1 (an acetyl-coenzyme A carboxylase-binding protein) transcripts were robustly upregulated in HFD-fed Siah2KO male BAT but not in females, whereas Agpat1 (acylglycerol-3-phosphate-O-acyltransferase-1) was upregulated in the HFD-fed Siah2KO animals independent of sex (Fig. 8a). Gene markers of mitochondrial function were regulated by Siah2 either in both sexes (Slc25a1, Tim44) or specifically in males (Cs, Mfn1) or females (Opa-1). In contrast, markers of thermogenesis displayed upregulation (Pgc1a, Dio2, Ucp1) or downregulation (Pdrm16) specifically in HFD-fed Siah2KO females (Fig. 8c). Markers of inflammation in brown fat displayed sex-by-genotype interactions (Fig. 8d). Thus, Siah2 deficiency corresponded to reduced mRNA expression of the macrophage-specific markers $F 4 / 80$ and $Y m 1$, a M2-macrophage specific marker [41] in males, but increased expression in females. Among cytokine/chemokine genes, Tnf alpha expression was suppressed by Siah2 deficiency in both sexes, whereas $\mathrm{Ccl} 2$ levels were significantly reduced Siah2KO males but highly upregulated in Siah2KO females. A similar sex-dependent effect was also observed for leptin, where loss of Siah2 led to reduced Leptin
mRNA expression in females, but not in males. However, the brown fat specific reduction in Leptin transcripts did not correspond to reduced circulating levels of leptin protein in the HFD-fed Siah2KO females compared to wild-type, although leptin protein levels were significantly lower in females compared to males on the high-fat diet (Fig. 8e).

To determine if the Siah2-mediated changes in thermogenic gene expression corresponded to increased expression of the encoded proteins, we carried out western blot analysis of PGC- $1 \alpha$ and UCP-1 expression in brown fat from the HFD-fed male and female mice. As shown in Fig. 9a, b, PGC1 $\alpha$ and UCP1 were increased in HFD-fed females, but not in males. Thus, Siah2-mediated sex-dependent transcriptional regulation of thermogenic genes (Fig. 8c) correlates with the increased levels of PGC- $1 \alpha$ and UCP1 protein in the brown adipose tissue of Siah2KO females. Given the evidence that Siah2 is an ER $\alpha$ transcriptional target [28, 42], we asked if ER $\alpha$ protein expression in brown fat is regulated by Siah2 deficiency. Notably, estrogens play a major role in regulating energy balance and thermogenesis through peripheral and central mechanisms [43], and ER $\alpha$ is also expressed in brown fat [44], although regulation of ER $\alpha$ signaling in brown fat per se is not well described. We anticipated ER $\alpha$ protein levels would be increased, corresponding to increased expression of ER $\alpha$ targets PGC1 $\alpha$ and UCP1. However, ER $\alpha$ levels are substantially downregulated in the absence of Siah2 (Fig. 9c, d) in the HFD-fed females, but unchanged 

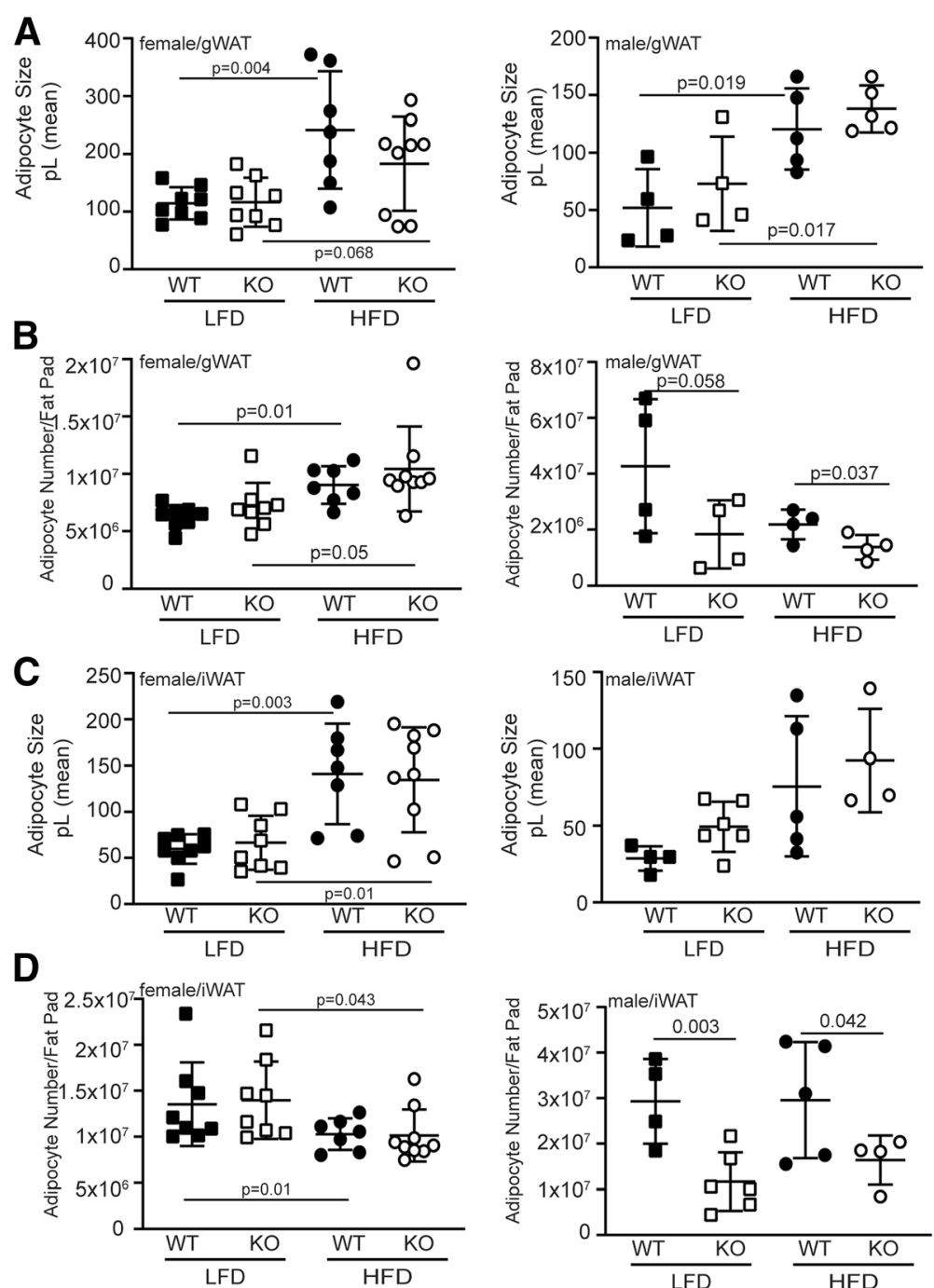

Fig. 4 Siah2KO affect adipocyte size and number in male, but not female gonadal and inguinal fat. Adipocyte size (area) in the LFD and HFD-fed female and male wild-type (WT) or Siah2KO (KO) mice was determined by automated cell counting of H\&E stained tissue using Image J software. Adipocyte number/fat pad was estimated by converting the adipocyte area to an adipocyte volume ( $\mathrm{pL}$ ) and converting fat pad weight to a volume using the density of lipids. a Adipocyte volume (pL) and $\mathbf{b}$ adipocyte number/fat pad for gonadal fat. c Adipocyte volume (pL) and d adipocyte number/fat pad for inguinal fat. Statistical significance was determined using two-tailed, unpaired $t$ test

in males. We then assayed the expression of the estrogenrelated receptor gamma (ERRY), an orphan nuclear receptor closely related to the estrogen receptors that is highly expressed in brown fat and other oxidative tissue [45]. Recent studies show ERRY is critical for maintaining the thermogenic capacity of brown fat [30] independent of PGC1 $\alpha$ expression [46]. As with ER $\alpha$, Siah2 deficiency educed ERRY protein levels in female, but not male brown fat $r$ (Fig. 9c, d). In contrast to protein levels, the transcript levels of ERalpha and ERRgamma gene expression appeared to increase in HFD-fed Siah2KO females, although the trend was either not significant or marginally significant (Fig. 9e).
Given the impact of estrogen-mediated hypothalamic AMPK activity on brown fat function, we assayed AMPK activity in the brown fat of the HFD-fed wild-type and Siah2KO mice. We found no Siah2-mediated effect on AMPK activity in the brown fat of the male or female mice (Fig. 9c, d). Finally, our earlier studies demonstrated that loss of Siah2 in obese male mice leads to increased PPAR $\gamma$ protein levels in gonadal fat [25] (Additional file $4 \mathrm{E}$ ). This prompted us to assay PPARY levels with Siah2 depletion in brown fat. As shown in Fig. 9c, d, Siah2 does not regulate PPARY in brown adipose tissue, although PPAR $\gamma$ trends down in the females and up in the males. While the limited number of 


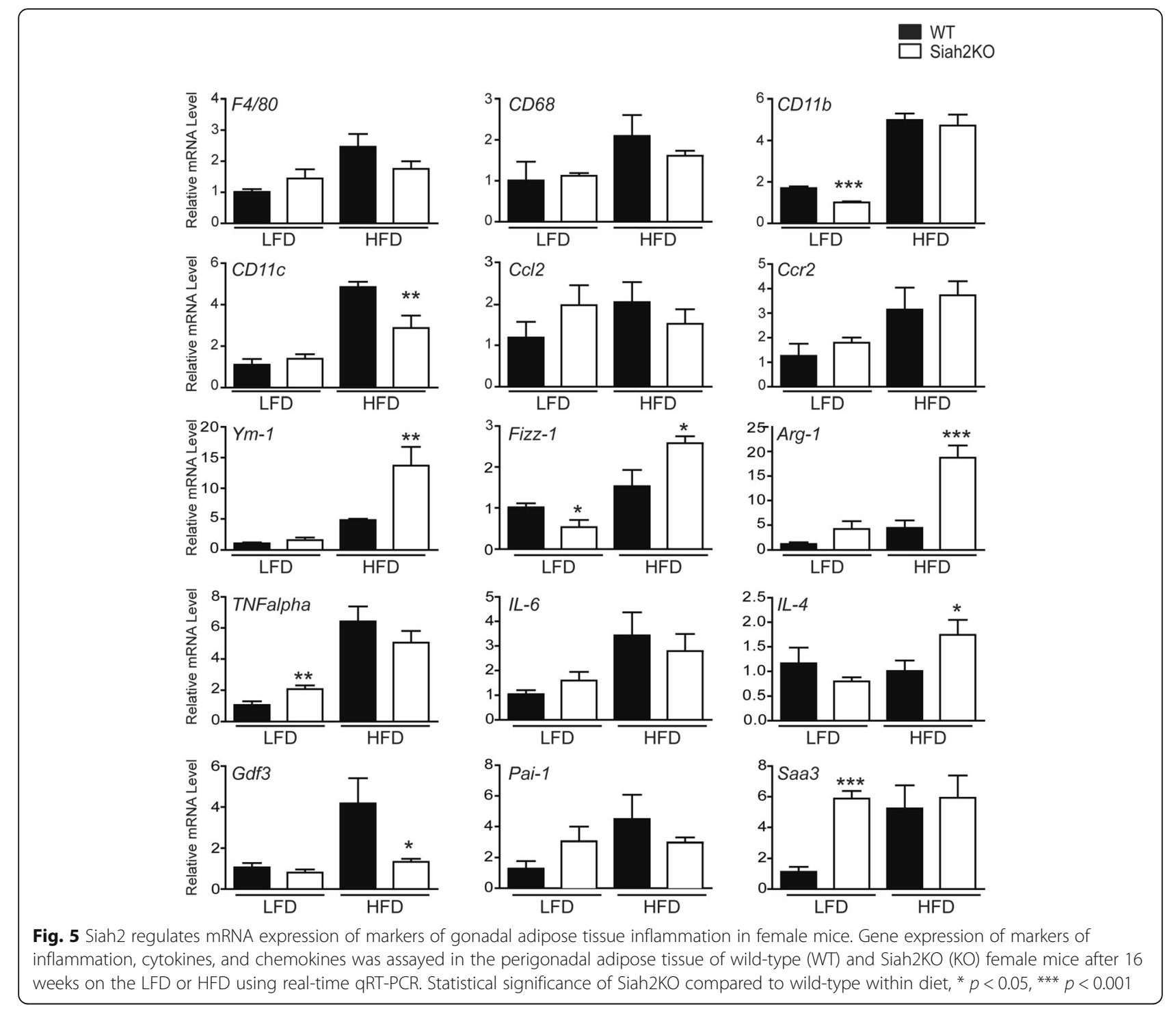

samples assayed may be insufficient to capture significant increases in PPARY in the brown fat of male mice, the results suggest Siah2-mediated regulation of select nuclear receptor protein levels depends on signaling events that are both fat depot-specific and sex-dependent. The results are summarized in Table 1.

\section{Discussion}

Earlier studies of the impact of Siah2 deficiency carried out in a male mouse model of diet-induced obesity showed the ubiquitin ligase Siah2 functions at the intersection of adipose tissue inflammation and insulin resistance in obesity. In the obese male mice, loss of Siah2 promotes lipid storage in hypertrophied adipocytes and reduces adipose tissue inflammation that leads to insulin resistance [25]. The HFD-fed male Siah2-deficient mice are a model of metabolically healthy obesity, a phenotype more typically associated with females [3] and attributed to the anti-inflammatory properties of estrogens [16]. The impact of Siah2 on adipose tissue inflammation coupled with estrogen-mediated regulation of Siah2 gene expression [28] prompted us to ask if there are sex-dependent effects of Siah2 deficiency on adipose tissue function in obesity. As found in the obese male mice, Siah2 in the high-fat-fed female mice regulates the relationship between white adipose tissue expansion via hypertrophy, adipose tissue inflammation, and insulin sensitivity. However, unlike the HFD-fed male mice [25], Siah2 deficiency in the HFD-fed females does not broadly dampen proinflammatory macrophage, cytokine, and chemokine expression. Instead, reduced crown-like structures in Siah2-deficient high-fat-fed females was associated with differential upregulation of markers of homeostatic resident macrophage and chemokines that promote alternative activation of macrophage. Genes encoding secreted factors such as TNF $\alpha$ and SAA3, that 

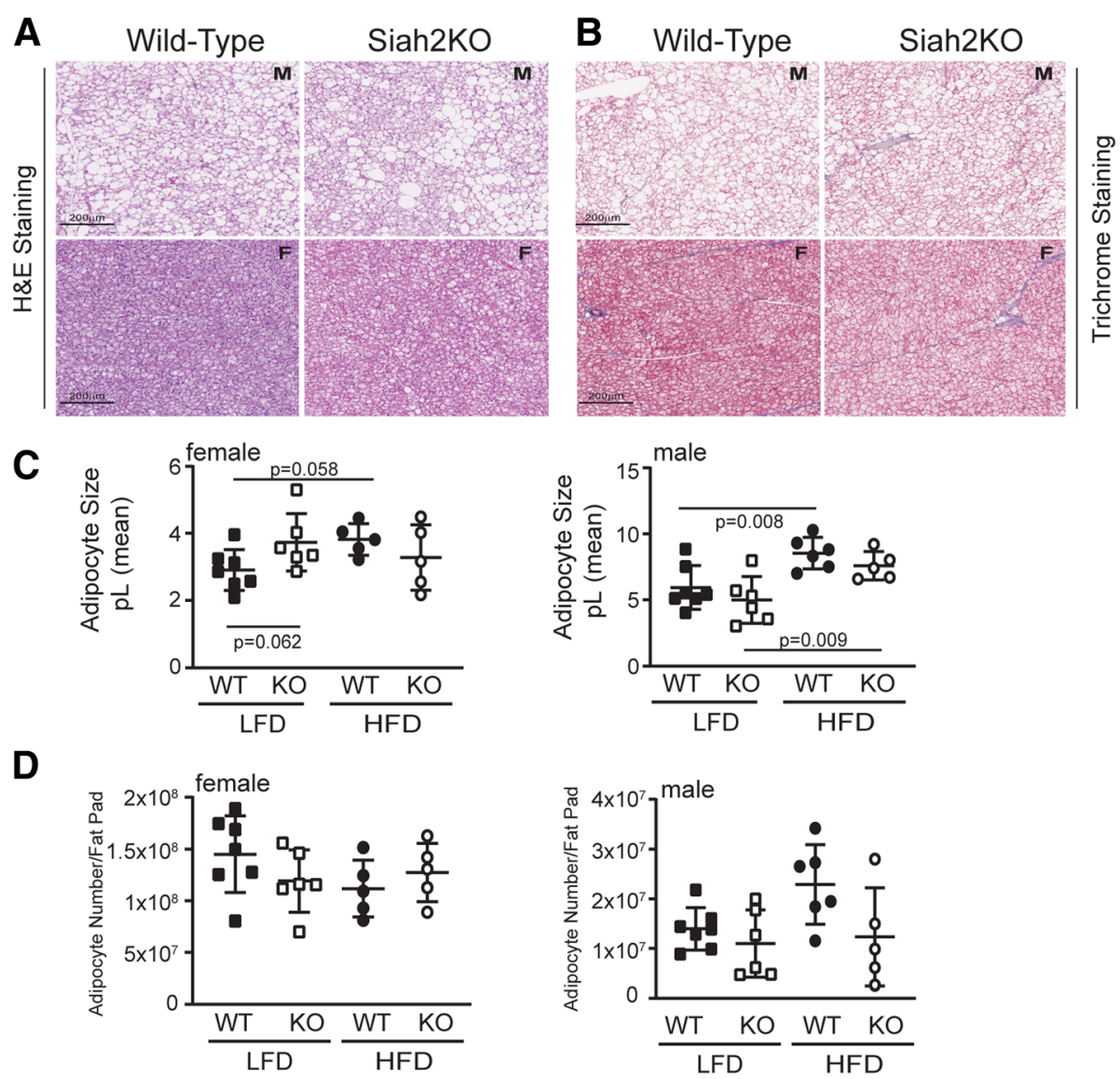

Fig. 6 Female brown adipose tissue accumulates less unilocular fat than males on a HFD. a H\&E and $\mathbf{b}$ trichrome staining of brown fat in wildtype and Siah2KO male (M) and female (F) mice fed a HFD for 16 weeks. c Adipocyte volume (pL) in the LFD and HFD-fed female wild-type (WT) or Siah2KO (KO) mice was based on adipocyte area determined by automated cell counting using Image J software of laminin stained brown adipose tissue. $\mathbf{d}$ Adipocyte number/fat pad was estimated by converting adipocyte area to an adipocyte volume ( $\mathrm{pL}$ ) and fat pad weight to a volume using the density of lipids. Statistical significance was determined using two-tailed, unpaired $t$ test

are generally associated with adipose tissue inflammation and insulin resistance [47], were also upregulated in the gonadal fat of HFD-fed Siah2KO female mice, despite their insulin sensitivity. This does not occur in obese Siah2KO male mice [25], but it agrees with recent evidence that SAA3 has anti-inflammatory properties and promotes a shift in macrophage toward a M2-like phenotype in adipose tissue [48]. Increased Tnf alpha mRNA in the context of a shift toward M2-like markers is also consistent with a positive role for pro-inflammatory stimulus in maintaining healthy adipose tissue as lipid storage capacity is challenged [49]. Thus, loss of Siah2 in female gonadal fat may differentially promote activation of resident M2-like macrophages and enhance adipose tissue remodeling to accommodate increased lipid storage demands in a sex-related manner.

In agreement with $\mathrm{Wu}$ et al. [50], we found that diet-induced fat expansion in the female gonadal fat occurred by increasing both hypertrophies of existing adipocytes and increasing the number of adipocytes while the male gonadal fat expanded by hypertrophy alone. In contrast, the inguinal and brown fat expanded solely by increasing the size of existing adipocytes in both sexes. Although the loss of Siah2 altered gene expression of inflammation markers, it did not change the mode of adipose tissue expansion in the HFD-fed females. In contrast, Siah2 deficiency significantly reduced the number of adipocytes in the white fat (and trending down in the BAT) of the HFD-fed males, lending further support for sex-related differences in the role of Siah2 in regulating the relationship between fat mass expansion and adipose tissue inflammation with obesity in white and brown fat.

Adipose tissue inflammation also occurs in obese brown adipose tissue as brown fat accumulates large unilocular lipid droplets characteristic of white adipose tissue in male mice [21]. Although leptin-mediated 

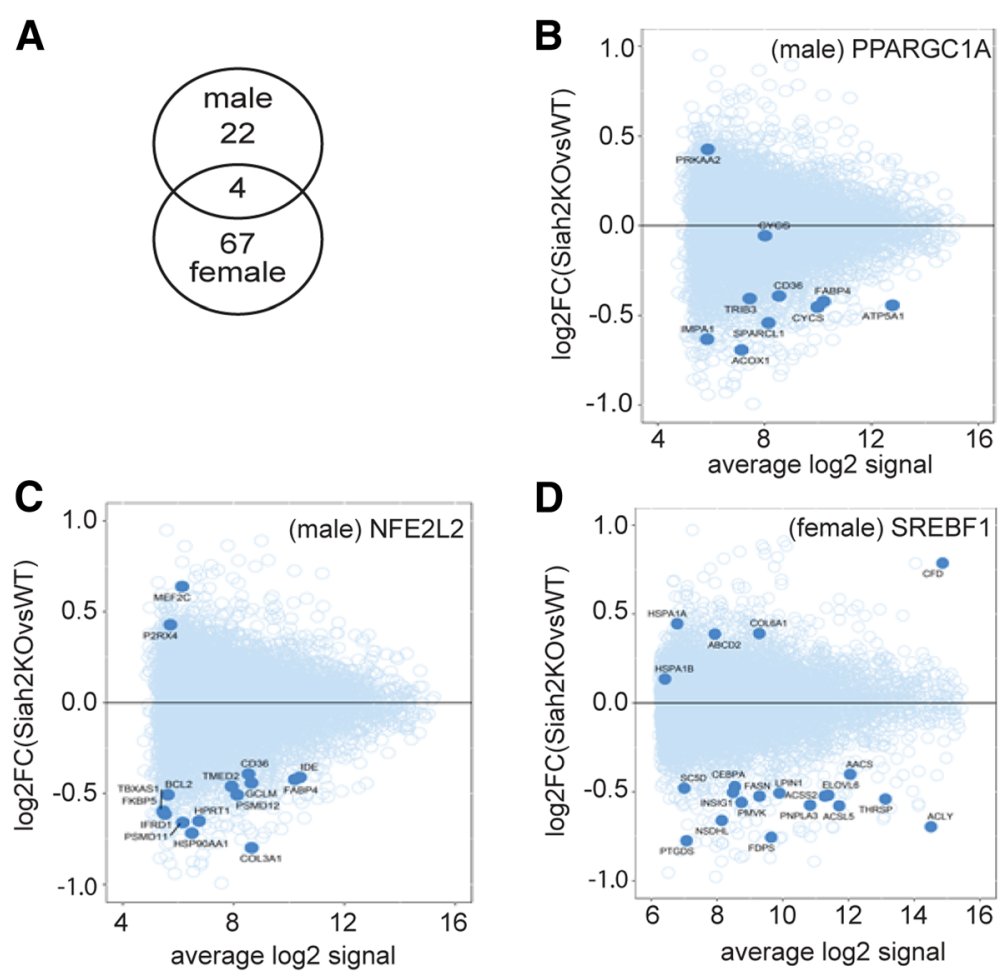

Fig. 7 Microarray analysis of brown fat transcriptomics in HFD-fed male and female mice. a-d Analysis of gene expression in male and female BAT samples. a Overlap of differentially expressed genes (nominal $P<0.001$, absolute fold-change $>1.5$ ) in male and female samples. b-d Mean-average plots for gene targets of transcription factors Nfe2l2 and Ppargcla (male BAT samples) and Srebf1 (female BAT samples), based on over-representation analysis in Ingenuity Pathway Analysis tool. Transcription factor target genes are shown as solid circles, whereas the remaining genes on the microarray are shown as open circles

signaling has been implicated in brown fat inflammation when white fat-like unilocular lipid droplets accumulate in the brown fat [21], loss of Siah2 appears to disrupt this connection as "whitening" of the brown fat in the HFD-fed wild-type male mice (and to a less extent in the Siah2KO male mice), and elevated leptin mRNA and protein levels were not accompanied by increased markers of inflammation. In contrast, reduced leptin mRNA and protein levels in the HFD-fed females were associated with robustly increased mRNA expression of a pro-inflammatory chemokine marker $(\mathrm{Ccl} 2)$ in the Siah2KO females.

While a relatively low number of genes are differentially regulated between the sexes in brown fat by Siah2 with a HFD challenge, decreased expression of genes supporting fatty acid oxidation in the Siah2KO males and lower levels of genes controlling lipogenesis in Siah2KO females are consistent with the morphological data with Siah2 deficiency in both sexes. Lipolysis (Atgl) is likely increased by Siah2 deficiency with a short fast, but other markers of lipid metabolism are not substantially regulated by sex or genotype. However, we cannot rule out significant changes in lipid metabolism with
Siah2 deficiency in the brown fat of either sex given the extensive post-translational regulation of lipid metabolism exemplified by ATGL-mediated control of lipid storage and release [51].

Most striking are the sex- and genotype-dependent differences related to inflammation and thermogenesis. The effect of Siah2 deficiency on brown fat inflammation in the HFD-fed males indicates generally reduced inflammatory responses to increased brown fat whitening in the obese Siah2KO males, as we observed in the male Siah2KO white adipose tissue. However, the pattern is more nuanced in females where the brown fat morphology is devoid of significant whitening or crown-like structures although proinflammatory markers are transcriptionally upregulated with Siah2 deficiency in the HFD-fed females. The Siah2-dependent increase in mRNA expression of the macrophage and proinflammatory chemokine markers in a setting of morphologically healthy brown fat in the females is consistent with a role for Siah2 in estrogen-mediated accelerated resolution of high-fatinduced inflammatory processes.

Minimal whitening of female brown fat was coupled with robust upregulation of thermogenic genes with a 


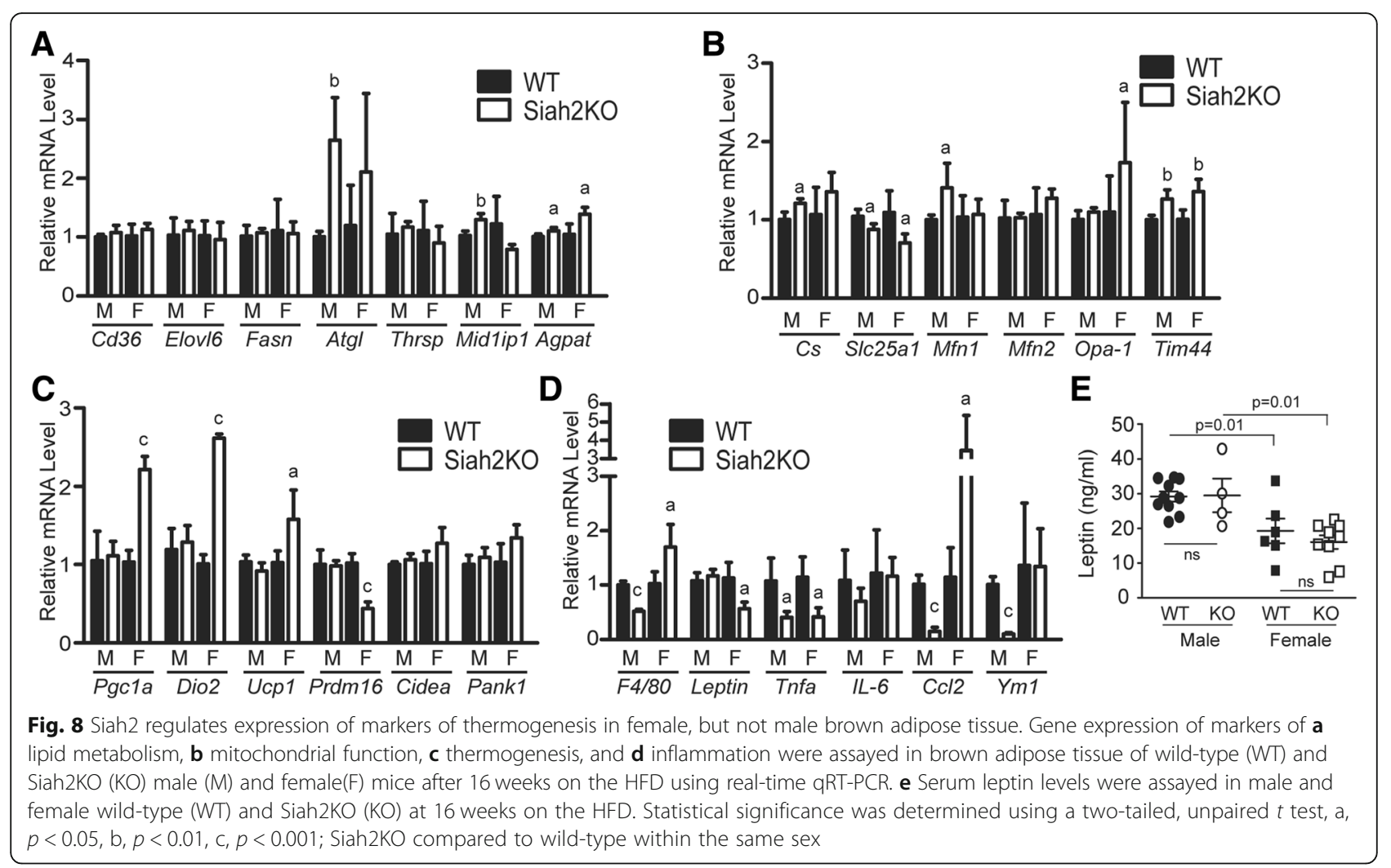

corresponding increase in $\mathrm{PGC} 1 \alpha$ and UCP1 protein levels in the Siah2-deficient HFD-fed females. This effect is absent in the male brown fat, indicating Siah2 in brown fat suppresses diet-induced thermogenic responses in a sex-dependent manner. Estrogens are well-described as acting centrally via estrogen receptor alpha $(E R \alpha)$-mediated inhibition of hypothalamic AMPK activity to stimulate brown fat thermogenesis via upregulation of Ucp1 and Pgc1a mRNA [29]. While the Siah2 deficiency model is a global deletion of Siah2, expression of Siah2 is not detected in the hypothalamus of wild-type C57BL/6 mice although it is found in the olfactory bulb and cerebellum [52]. This suggests the effect of Siah2 on thermogenic markers more likely occurs peripherally. ER $\alpha$ is also expressed in male and female brown fat, but there is less data on the direct effects of estrogens on brown fat function.

The sex-related effect of Siah2 on thermogenic gene expression in the female brown fat did not depend on AMPK signaling in brown fat, and unexpectedly, loss of Siah2 in the HFD-fed female brown fat substantially reduced expression of ER $\alpha$ and ERR $\gamma$ proteins while reductions in PPARy protein levels were not statistically significant. Moreover, reduced PPAR $\gamma$ protein expression contrasts with the effect of Siah2 deficiency on PPARy protein levels in white fat of HFD-fed obese male mice
[25] and (Additional file 4 E), suggesting both sex- and fat depot-specific effects of Siah2 in nuclear receptor protein levels. Nonetheless, Siah2 deficiency stimulates expression of thermogenic genes while decreasing the levels of the transcription factors that regulate thermogenic gene expression. This most likely occurs via a post-transcriptional mechanism as $E R \alpha$ and $E R R g$ gene expression increased with loss of Siah2, consistent with a feedback loop to maintain protein expression in the context of accelerated receptor turnover [53].

In a series of studies, the O'Malley group established that ligand-dependent activation of ER $\alpha$ is coupled to proteasome-dependent degradation of the activated receptor $[54,55]$. Our data demonstrates the enhanced degradation of ER $\alpha$ and ERR $\gamma$ in the absence of Siah2. This is unexpected given the existing paradigm for the role of Siah2 as part of a nuclear receptor corepressor complex that restrains the activity of nuclear receptors. According to this scenario, Siah2 interacts with the corepressor $\mathrm{N}-\mathrm{CoR}$ and promotes ligand-dependent nuclear receptor activity by targeting $\mathrm{N}-\mathrm{CoR}$ for proteasomal degradation [56]. If Siah2 were regulating ER $\alpha$ and ERRY protein levels by dismissing a corepressor, loss of Siah2 is expected to increase ER $\alpha$ and ERR $\gamma$ protein levels as $\mathrm{N}-\mathrm{CoR}$ remains bound to the receptor, disrupting ligand-dependent activation and proteasome-dependent 
A

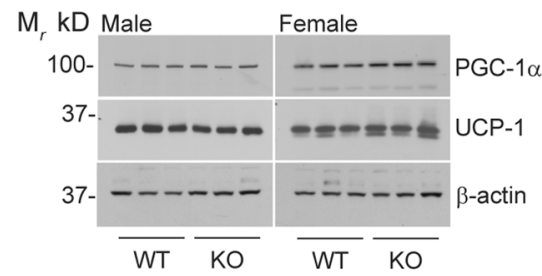

C

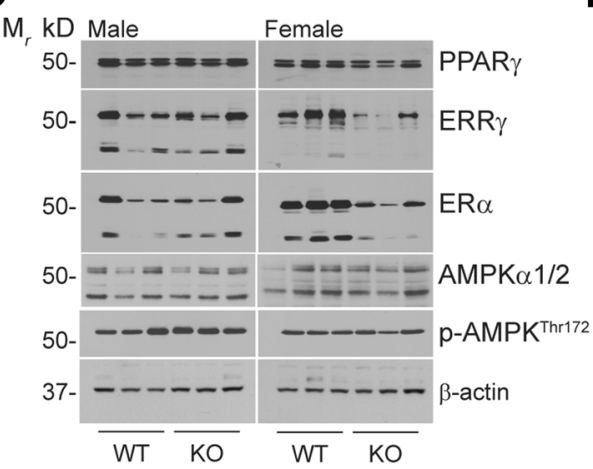

B

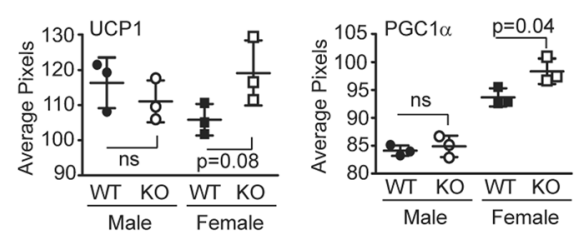

D
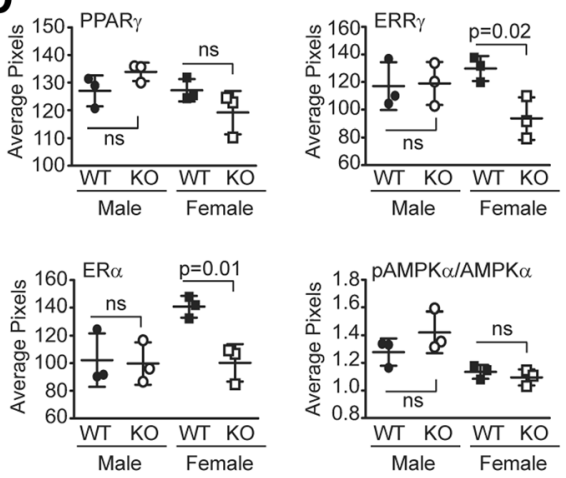

E
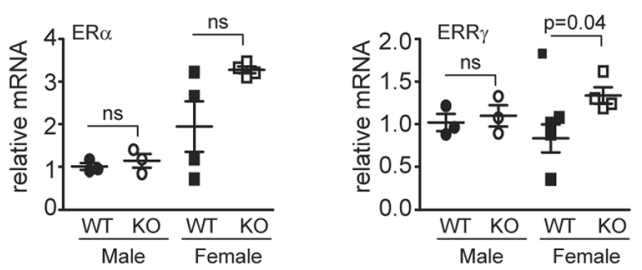

Fig. 9 Loss of Siah2 upregulates thermogenic proteins, but downregulates ERa and ERRY in brown adipose tissue independent of changes in gene expression in female, not male mice fed a HFD. a PGC1a and UCP1 and c PPARY, ERRY, ERa, AMPK1/2, and phosphorylated AMPK levels in brown adipose tissue were assayed via western blot analysis in male and female wild-type (WT) and Siah2KO (KO) mice after 16 weeks on the HFD and $\mathbf{b}$, d quantified using Un-Scan-It software. e Gene expression of Eralpha and Errgamma was analyzed via real-time qRT-PCR. $\beta$-actin is included as a loading control in a, c. Statistical significance was determined using a two-tailed, unpaired $t$ test

degradation of the receptors as well as N-CoR. Our result suggests Siah2 acts by a different mechanism to restrain activation and turnover of ER $\alpha$ and ERR $\gamma$ to control brown fat thermogenesis in females.

However, our study has several limitations. While the data supports a sex-related role for Siah2 in adaptive thermogenesis, we did not directly assay thermogenesis or energy expenditure and the ability to adapt to cold temperatures in the wild-type and Siah2-deficient male and female mice. We also did not carry out the studies of Siah2 deficiency in the absence of either ER $\alpha$ or ERR $y$ to provide conclusive evidence of a role for Siah2 in estrogen-mediated regulation of brown fat function. As we show in this study, transcriptional changes may not reflect (or may be inversely related to) post-transcriptional levels of the encoded protein. Thus, transcriptional changes in inflammatory markers or lipid metabolism genes do not provide direct evidence of changes in the levels or activity of the encoded protein. We attempt to overcome this limitation by assaying the
mRNA expression of a range of inflammatory markers coupled with morphological changes and selected protein expression to gain an understanding of a regulatory pattern indicative of adipose tissue inflammation. Finally, although our study is carried out in mice, the relatively high levels of brown fat observed in the female mice mirrors the higher levels found in women compared to men. The female mice also show resilience to the metabolic effects of adiposity that occur in premenopausal women. These similarities suggest the mouse model of Siah2 deficiency may provide important and relevant mechanistic insights into sex-related differences in men and women in response to obesity.

\section{Conclusion}

The ubiquitin ligase Siah2 is an important mediator of the relationship between adipose tissue expansion via hypertrophy, adipose tissue inflammation, and impaired glucose tolerance in male and female mice that are 
Table 1 Summary of sex-related differences in Siah2KO adipose tissue

\begin{tabular}{|c|c|c|}
\hline Siah2KO phenotype & $\begin{array}{l}\text { Females (compared to WT and HFD } \\
\text { unless otherwise noted) }\end{array}$ & $\begin{array}{l}\text { Males (compared to WT and HFD } \\
\text { unless otherwise noted) }\end{array}$ \\
\hline \multicolumn{3}{|l|}{ Body composition } \\
\hline Baseline fat mass (WT and $\mathrm{KO}$ ) & Higher than males & Lower than females \\
\hline Rate of gonadal fat mass gain (WT) & Lower than males & Higher than females \\
\hline Rate of gonadal fat mass gain (KO) & Higher than males & Lower than females \\
\hline Fat mass gain in BAT & Higher & Lower \\
\hline BAT relative to body weight (WT and $\mathrm{KO}$ ) & Higher than males & Lower than females \\
\hline Adipocyte size & Larger & Larger \\
\hline Percent fat mass at 4 months & Higher than males & Lower than females \\
\hline Body weight, LFD & Higher & Higher \\
\hline Body weight, HFD & Attenuated vs. WT & Higher \\
\hline \multicolumn{3}{|l|}{ Biochemical measurements } \\
\hline Glucose tolerance & Tolerant & Tolerant $^{23}$ \\
\hline Insulin tolerance & Tolerant & Tolerant $^{23}$ \\
\hline Fasting glucose & Unchanged & Lower $^{23}$ \\
\hline Fasting insulin, LFD & Higher & Unchanged ${ }^{23}$ \\
\hline Fasting insulin, HFD & Unchanged & Lower $^{23}$ \\
\hline Circulating free fatty acids & Unchanged (LFD), lower (HFD) & Lower $^{23}$ (LFD and HFD) \\
\hline Circulating triglycerides & Unchanged & Lower $^{23}$ \\
\hline \multicolumn{3}{|l|}{ Inflammation and fibrosis markers in gWAT } \\
\hline Crown-like structures & Fewer & Fewer \\
\hline Adipose fibrosis & Lower & Lower \\
\hline Macrophage marker (F4/80, CD68, CD11b) & No change & Lower $^{23}$ \\
\hline M1-macrophage marker (CD11c) & Lower & Lower $^{23}$ \\
\hline M2-macrophage marker (Ym1, Arg1, IL4) & Higher & Higher $(\operatorname{Arg} 1)^{23}$ \\
\hline Pro-inflammatory markers (TNFa, IL6, Ccl2, Ccr2) & Unchanged & Lower $^{23}$ \\
\hline Pai-1, Saa3 gene expression & Unchanged & Lower $^{23}$ \\
\hline Gdf3 gene expression & Lower & Lower $^{23}$ \\
\hline \multicolumn{3}{|l|}{ Thermogenesis markers in BAT } \\
\hline ER-a/ERR- $\gamma$ gene expression & Higher & No change \\
\hline ER-a/ERR- $y$ protein expression & Lower & No change \\
\hline PCG1a, Dio2, Ucp1 gene expression & Higher & No change \\
\hline PCG1a, Dio2, Ucp1 protein expression & Higher & No change \\
\hline
\end{tabular}

BAT brown adipose tissue, gWAT gonadal white adipose tissue, LFD low-fat diet, HFD high-fat diet, KO Siah2 global knockout, WT wild-type

${ }^{23}$ Data reported in reference [23]

chronically over-fed with a high-fat diet. There are similarities between the sexes in the impact of Siah2 deficiency on morphological evidence of white adipose tissue inflammation. However, important sex-related differences in expression of genes encoding markers of inflammation suggest the underlying mechanism responsible for reduced inflammation in the adipose tissue differs between HFD male and females. The effect of Siah2 deficiency on adipose tissue function extends to brown fat with substantial sex-related effects of Siah2 on the regulation of thermogenic markers in the brown fat of the HFD-fed mice. The stimulation of thermogenic gene and protein expression and regulation of ER $\alpha$ and ERR $\gamma$ protein levels only in the Siah2-deficient females suggests that Siah2 restrains the impact of ER $\alpha$ and ERR $\gamma$ proteins on brown fat function in females, but not in male mice. This finding further underscores the sex-dependent roles of Siah2 in key metabolic tissues when challenged with chronic excess calorie intake. 


\section{Additional files}

Additional file 1: This is an excel file (.xlsx) titled Supporting Information Related to Gene Expression Analysis (XLSX $12 \mathrm{~kb}$ )

Additional file 2: This is an excel file (.x|sx) titled Antibody Information (XLSX $11 \mathrm{~kb}$ )

Additional file 3: This is a tiff file titled Additional Information on White and Brown Fat Morphology (TIF 6267 kb)

Additional file 4: This is a tiff file title Additional Information on Metabolic and Inflammatory markers and PPARy protein expression is Siah2-deficient male mice (TIF $233 \mathrm{~kb}$ )

\section{Acknowledgements}

The authors thank Karlee Castello for her excellent technical assistance.

\section{Funding}

This research is supported by the National Institutes of Health (NIDDK, R01DK099625 to ZEF and 2 U54 GM104940 (Louisiana Clinical and Translational Science Center) to SG. This work used the Cell Biology and Bioimaging Core and the Genomics Core facilities at Pennington Biomedical Research Center that are supported in part by COBRE (NIH8 P30GM118430-01) and NORC (NIH P30 DK072476) center grants from the National Institutes of Health. This research was also partially supported by the National Medical Research Council, Ministry of Health, Singapore (WBS R913200076263 to SG).

\section{Availability of data and materials}

The data supporting the conclusions of this article are included within the article and the additional files (Additional files 1 and 2) except the entire brown adipose tissue microarray dataset. That dataset is deposited in GEO (\#GSE123990).

\section{Authors' contributions}

ULT and TM contributed to the animal care, sample collection, and data and statistical analysis. SG, JLT, YY, TD, DB, and ZEF contributed to the data analysis and interpretation. SG, DB, and ZEF contributed to the experimental design. SG and ZEF wrote the manuscript. All authors read and approved the final draft.

\section{Ethics approval and consent to participate}

All animal experiments were conducted in accordance with the National Institutes of Health Guide for the Care and Use of Laboratory Animals (8th edition) and approved by the Pennington Biomedical Research Center Animal Care and Use Committee (protocol \#1030).

\section{Consent for publication}

Not applicable

\section{Competing interests}

The authors declare that they have no competing interests.

\section{Publisher's Note}

Springer Nature remains neutral with regard to jurisdictional claims in published maps and institutional affiliations.

\section{Author details \\ ${ }^{1}$ Pennington Biomedical Research Center, Baton Rouge, LA 70808, USA. ${ }^{2}$ Cardiovascular and Metabolic Disease Program and Center for Computational Biology, Duke-NUS Graduate Medical School, Singapore, Singapore.}

Received: 18 December 2018 Accepted: 31 March 2019 Published online: 15 April 2019

\section{References}

1. Hevener A, Reichart D, Janez A, Olefsky J. Female rats do not exhibit free fatty acid-induced insulin resistance. Diabetes. 2002;51(6):1907-12.
2. Macotela Y, Boucher J, Tran T, Kahn CR. Sex and depot differences in adipocyte insulin sensitivity and glucose metabolism. Diabetes. 2009;58(4):803-12.

3. Medrikova D, Jilkova ZM, Bardova K, Janovska P, Rossmeisl M, Kopecky J. Sex differences during the course of diet-induced obesity in mice: adipose tissue expandability and glycemic control. Int J Obes. 2012;36(2):262-72.

4. Frank AP, Palmer BF, Clegg DJ. Do estrogens enhance activation of brown and beiging of adipose tissues? Physiol Behav. 2018;187:24-31.

5. Karastergiou K, Fried SK. Cellular mechanisms driving sex differences in adipose tissue biology and body shape in humans and mouse models. Adv Exp Med Biol. 2017;1043:29-51.

6. Karastergiou K, Smith SR, Greenberg AS, Fried SK. Sex differences in human adipose tissues - the biology of pear shape. Biol Sex Differ. 2012;3(1):13.

7. White UA, Tchoukalova YD. Sex dimorphism and depot differences in adipose tissue function. Biochim Biophys Acta. 2014;1842(3):377-92.

8. Elffers TW, de Mutsert R, Lamb HJ, de Roos A, Willems van Dijk K, Rosendaal FR, et al. Body fat distribution, in particular visceral fat, is associated with cardiometabolic risk factors in obese women. PLoS One. 2017:12(9):e0185403.

9. Palmer BF, Clegg DJ. The sexual dimorphism of obesity. Mol Cell Endocrinol. 2015;402:113-9.

10. Meyer MR, Clegg DJ, Prossnitz ER, Barton M. Obesity, insulin resistance and diabetes: sex differences and role of oestrogen receptors. Acta Physiol (Oxf). 2011;203(1):259-69.

11. Piché M-Ë, Weisnagel SJ, Corneau L, Nadeau A, Bergeron J, Lemieux S. Contribution of abdominal visceral obesity and insulin resistance to the cardiovascular risk profile of postmenopausal women. Diabetes. 2005;54(3):770-7

12. Mozumdar A, Liguori G. Persistent increase of prevalence of metabolic syndrome among U.S. adults: NHANES III to NHANES 1999-2006. Diabetes Care. 2011;34(1):216-9.

13. White UA, Fitch MD, Beyl RA, Hellerstein MK, Ravussin E. Differences in in vivo cellular kinetics in abdominal and femoral subcutaneous adipose tissue in women. Diabetes. 2016:65(6):1642-7.

14. Gregor MF, Hotamisligil GS. Inflammatory mechanisms in obesity. Annu Rev mmunol. 2011;29:415-45.

15. Greenberg AS, Obin MS. Obesity and the role of adipose tissue in inflammation and metabolism. Am J Clin Nutr. 2006;83(2):461S-5S.

16. Davis KE, Neinast MD, Sun K, Skiles WM, Bills JD, Zehr JA, et al. The sexually dimorphic role of adipose and adipocyte estrogen receptors in modulating adipose tissue expansion, inflammation, and fibrosis. Mol Metab. 2013;2(3):227-42.

17. Gonzalez-Garcia I, Tena-Sempere M, Lopez M. Estradiol regulation of brown adipose tissue thermogenesis. Adv Exp Med Biol. 2017;1043:315-35.

18. Cypess AM, Lehman S, Williams G, Tal I, Rodman D, Goldfine AB, et al. Identification and importance of brown adipose tissue in adult humans. $\mathrm{N}$ Engl J Med. 2009:360(15):1509-17.

19. Lee P, Greenfield JR, Ho KKY, Fulham MJ. A critical appraisal of the prevalence and metabolic significance of brown adipose tissue in adult humans. Am J Physiol Endocrinol Metab. 2010;299(4):E601-E6.

20. Shimizu I, Walsh K. The whitening of brown fat and its implications for weight management in obesity. Curr Obes Rep. 2015;4(2):224-9.

21. Kotzbeck P, Giordano A, Mondini E, Murano I, Severi I, Venema W, et al. Brown adipose tissue whitening leads to brown adipocyte death and adipose tissue inflammation. J Lipid Res. 2018:59(5):784-94.

22. Cinti S, Mitchell G, Barbatelli G, Murano I, Ceresi E, Faloia E, et al. Adipocyte death defines macrophage localization and function in adipose tissue of obese mice and humans. J Lipid Res. 2005;46(11):2347-55.

23. Monteiro R, Teixeira D, Calhau C. Estrogen signaling in metabolic inflammation. Mediat Inflamm. 2014:2014:615917.

24. Villa A, Rizzi N, Vegeto E, Ciana P, Maggi A. Estrogen accelerates the resolution of inflammation in macrophagic cells. Sci Rep. 2015:5:15224.

25. Kilroy G, Carter LE, Newman S, Burk DH, Manuel J, Moller A, et al. The ubiquitin ligase Siah2 regulates obesity-induced adipose tissue inflammation. Obesity. 2015;23(11):2223-32

26. Kilroy G, Kirk-Ballard H, Carter LE, Floyd ZE. The ubiquitin ligase Siah2 regulates PPARgamma activity in adipocytes. Endocrinology. 2012;153(3):1206-18.

27. Tontonoz P, Spiegelman BM. Fat and beyond: the diverse biology of PPARgamma. Annu Rev Biochem. 2008;77:289-312.

28. Frasor J, Danes JM, Funk CC, Katzenellenbogen BS. Estrogen downregulation of the corepressor $\mathrm{N}-\mathrm{CoR}$ : mechanism and implications for 
estrogen derepression of N-CoR-regulated genes. Proc Natl Acad Sci U S A. 2005;102(37):13153-7.

29. Martinez de Morentin PB, Gonzalez-Garcia I, Martins L, Lage R, FernandezMallo D, Martinez-Sanchez N, et al. Estradiol regulates brown adipose tissue thermogenesis via hypothalamic AMPK. Cell Metab. 2014;20(1):41-53.

30. Ahmadian M, Liu S, Reilly SM, Hah N, Fan W, Yoshihara E, et al. ERRgamma preserves brown fat innate thermogenic activity. Cell Rep. 2018;22(11):2849-59

31. Frew IJ, Hammond VE, Dickins RA, Quinn JM, Walkley CR, Sims NA, et al. Generation and analysis of Siah2 mutant mice. Mol Cell Biol. 2003; 23(24):9150-61.

32. McGuinness OP, Ayala JE, Laughlin MR, Wasserman DH. NIH experiment in centralized mouse phenotyping: the Vanderbilt experience and recommendations for evaluating glucose homeostasis in the mouse. Am $J$ Physiol Endocrinol Metab. 2009;297(4):E849-55.

33. Baldi $\mathrm{P}$, Long AD. A Bayesian framework for the analysis of microarray expression data: regularized $\mathrm{t}$-test and statistical inferences of gene changes. Bioinformatics. 2001;17(6):509-19.

34. Benjamini YaH Y. Controlling the false discovery rate: a practical and powerful approach to multiple testing. J R Stat Soc Ser B. 1995;57:289-300.

35. Ferguson BS, Nam H, Hopkins RG, Morrison RF. Impact of reference gene selection for target gene normalization on experimental outcome using real-time aRT-PCR in adipocytes. PLoS One. 2010;5(12):e15208.

36. Kilroy G, Burk DH, Floyd ZE. Siah2 protein mediates early events in commitment to an adipogenic pathway. J Biol Chem. 2016;291(53):27289-97.

37. Rutkowski JM, Stern JH, Scherer PE. The cell biology of fat expansion. J Cell Biol. 2015;208(5):501-12.

38. Kim SM, Lun M, Wang M, Senyo SE, Guillermier C, Patwari P, et al. Loss of white adipose hyperplastic potential is associated with enhanced susceptibility to insulin resistance. Cell Metab. 2014;20(6):1049-58.

39. Smorlesi A, Frontini A, Giordano A, Cinti S. The adipose organ: whitebrown adipocyte plasticity and metabolic inflammation. Obes Rev. 2012;13(Suppl 2):83-96

40. van den Berg SM, van Dam AD, Rensen PC, de Winther MP, Lutgens E. Immune modulation of brown(ing) adipose tissue in obesity. Endocr Rev. 2017;38(1):46-68

41. Raes G, Van den Bergh R, De Baetselier P, Ghassabeh GH, Scotton C, Locati M, et al. Arginase-1 and Ym1 are markers for murine, but not human, alternatively activated myeloid cells. J Immunol. 2005;174(11):6561 author reply -2.

42. Pan YF, Wansa KDSA, Liu MH, Zhao B, Hong SZ, Tan PY, et al. Regulation of estrogen receptor-mediated long range transcription via evolutionarily conserved distal response elements. J Biol Chem. 2008;283(47):32977-88.

43. Mauvais-Jarvis F, Clegg DJ, Hevener AL. The role of estrogens in control of energy balance and glucose homeostasis. Endocr Rev. 2013;34(3):309-38.

44. Drew BG, Hamidi H, Zhou Z, Villanueva CJ, Krum SA, Calkin AC, et al. Estrogen receptor (ER) alpha-regulated lipocalin 2 expression in adipose tissue links obesity with breast cancer progression. J Biol Chem. 2015;290(9):5566-81

45. Giguere V. Transcriptional control of energy homeostasis by the estrogenrelated receptors. Endocr Rev. 2008;29(6):677-96.

46. Dixen K, Basse AL, Murholm M, Isidor MS, Hansen LH, Petersen MC, et al. ERRgamma enhances UCP1 expression and fatty acid oxidation in brown adipocytes. Obesity (Silver Spring). 2013;21(3):516-24.

47. Yang RZ, Lee MJ, Hu H, Pollin TI, Ryan AS, Nicklas BJ, et al. Acute-phase serum amyloid a: an inflammatory adipokine and potential link between obesity and its metabolic complications. PLoS Med. 2006;3(6):e287.

48. Ather JL, Poynter ME. Serum amyloid $A 3$ is required for normal weight and immunometabolic function in mice. PLoS One. 2018;13(2):e0192352.

49. Wernstedt Asterholm I, Tao C, Morley TS, Wang QA, Delgado-Lopez F, Wang $\mathrm{ZV}$, et al. Adipocyte inflammation is essential for healthy adipose tissue expansion and remodeling. Cell Metab. 2014;20(1):103-18.

50. Wu Y, Lee MJ, Ido Y, Fried SK. High-fat diet-induced obesity regulates MMP3 to modulate depot- and sex-dependent adipose expansion in C57BL/6J mice. Am J Physiol Endocrinol Metab. 2017;312(1):E58-71.

51. Cerk IK, Wechselberger L, Oberer M. Adipose triglyceride lipase regulation: an overview. Curr Protein Pept Sci. 2018;19(2):221-33.

52. Lein ES, Hawrylycz MJ, Ao N, Ayres M, Bensinger A, Bernard A, et al. Genome-wide atlas of gene expression in the adult mouse brain. Nature. 2007:445(7124):168-76.

53. Bendtsen KM, Jensen MH, Krishna S, Semsey S. The role of mRNA and protein stability in the function of coupled positive and negative feedback systems in eukaryotic cells. Sci Rep. 2015;5:13910.
54. Lonard DM, Nawaz Z, Smith CL, O'Malley BW. The 26S proteasome is required for estrogen receptor-alpha and coactivator turnover and for efficient estrogen receptor-alpha transactivation. Mol Cell. 2000;5(6):939-48.

55. Nawaz Z, Lonard DM, Dennis AP, Smith CL, O'Malley BW. Proteasomedependent degradation of the human estrogen receptor. Proc Natl Acad Sci U S A. 1999;96(5):1858-62.

56. Zhang J, Guenther MG, Carthew RW, Lazar MA. Proteasomal regulation of nuclear receptor corepressor-mediated repression. Genes Dev. 1998;12(12):1775-80.
Ready to submit your research? Choose BMC and benefit from:

- fast, convenient online submission

- thorough peer review by experienced researchers in your field

- rapid publication on acceptance

- support for research data, including large and complex data types

- gold Open Access which fosters wider collaboration and increased citations

- maximum visibility for your research: over $100 \mathrm{M}$ website views per year

At BMC, research is always in progress.

Learn more biomedcentral.com/submissions 